\title{
Painless stress fractures in diabetic neuropathic feet
}

\author{
Geoffrey Gill, Susan Benbow, Solomon Tesfaye, Edward Kaczmarczyk, Linda Kaye
}

\begin{abstract}
Summary
We describe two patients with diabetes mellitus and associated neuropathy, who presented with painless foot swelling and no history of trauma. X-Rays revealed recent underlying fractures - in one of a metatarsus, and the other of a proximal phalanx. These were assumed to be 'stress' fractures unassociated with pain because of the severe sensory neuropathy. Though spontaneous fractures in neuropathic feet have been previously described, they almost always occur in association with Charcot joints, and are usually painful. The differential diagnosis of acute swelling in the foot of a diabetic patient with sensory neuropathy should include stress fracture.
\end{abstract}

Keywords: diabetes, neuropathy, stress fractures

Fractures of various bones of the foot may occur as a complication of neuropathic arthropathy, ${ }^{1-5}$ and occasionally in the presence of simple neuropathy, ${ }^{6,7}$ although in most cases the fractures are associated with pain. We describe two patients who presented to our Diabetic Foot Clinic with completely painless stress fractures of the foot, as an apparent complication of neuropathy but without the presence of neuropathic arthropathy.

\section{Case reports}

Case 1

A 60-year-old man developed non-insulindependent diabetes (NIDDM) and at presentation, had well-established sensory neuropathy of the feet, with a left foot plantar ulcer and neuropathic pain. The ulcer healed, and his diabetes was well controlled on dietary treatment alone $\left(\mathrm{HbA}_{1 \mathrm{c}} 6.6 \%\right.$, non-diabetic range $3.8-5.4 \%$ ). He had background retinopathy, but no nephropathy, or evidence of large vessel disease. Twelve months after diagnosis, he presented to the Diabetic Foot Clinic with painless swelling of the left second toe, of three days duration. There was no history of trauma. On examination the toe was swollen and slightly warm, but there was no other evidence of infection. Signs of marked sensory loss in the feet were still present, especially of touch and pain sensation. An Xray of the toe showed a fracture of the proximal phalanx (figure 1). With rest and support, the swelling subsided and the fracture healed radiologically over the next two months.

\section{Case 2}

A 42-year-old woman with insulin-dependent diabetes (IDDM) of 18 years duration presented with swelling of the right foot but no pain or history of trauma. She was known to have retinopathy, neuropathy and early nephropathy but no macrovascular disease. The feet had significantly reduced sensation, but there was no erythema or tenderness. Glycaemic control at the time was poor $\left(\mathrm{HbA}_{\mathrm{lc}}\right.$ $12.6 \%$ ), on a tid Actrapid and evening Insulatard regime. Cellulitis of the foot was

\begin{tabular}{|l|}
\hline Summary/learning points \\
\hline - painless stress fractures may occur in diabetic \\
patients with neuropathy \\
- in such cases the presenting feature is usually \\
unexplained swelling \\
- misdiagnoses such as gout or cellulitis may be \\
made \\
- unexplained swelling of a diabetic neuropathic \\
foot requires an X-ray examination \\
\hline
\end{tabular}

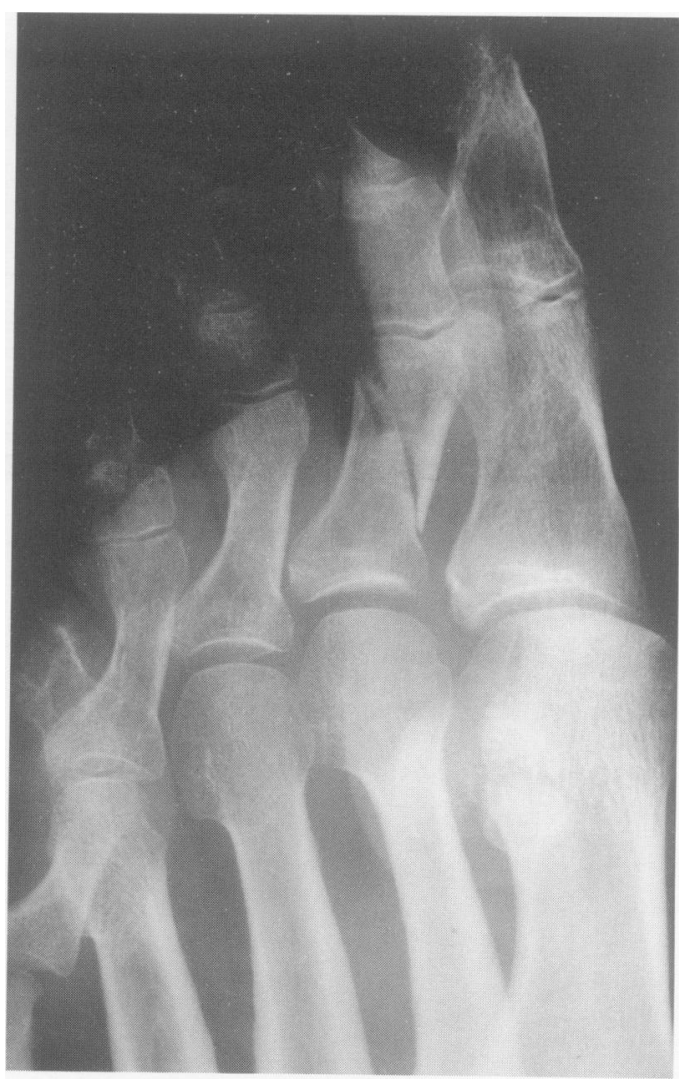

Figure 1 Oblique fracture of left second proximal phalanx in a 61-year-old man with NIDDM and neuropathic feet 


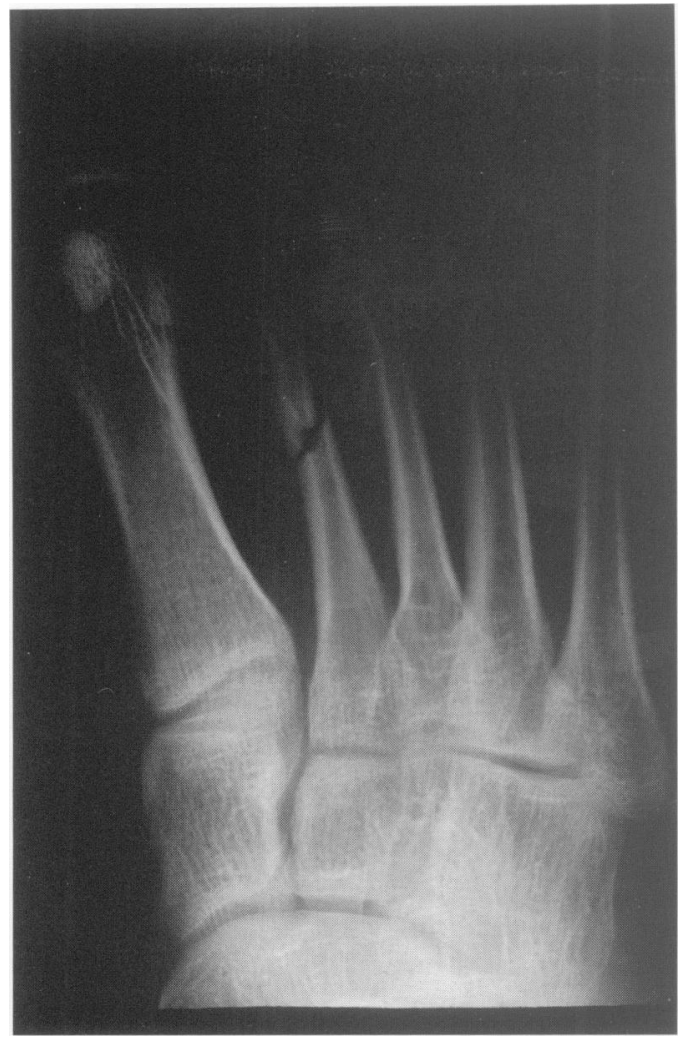

Figure 2 Fracture of the shaft of the right second metatarsus in a 42-year-old woman with IDDM and neuropathic feet

considered, but an X-ray showed a fracture of the shaft of the second metatarsus (figure 2). Over the next month the swelling subsided and the fracture united radiologically. The patient could remember no episode of injury to account for the fracture.

\section{Discussion}

Both these patients had severely neuropathic feet, complicating IDDM in one and NIDDM in the other. In neither was there evidence of Charcot-type neuro-arthropathy, nor significant radiological osteopenia. Both presented with localised swelling which was quite painless, and in neither was there any history of

1 Sinha S, Munichoodapa CS, Kozak GP. Neuroarthropathy (Charcot joints) in diabetes mellitus. Medicine 1972; 51: 191-210.

2 Clohisy DR, Thompson RC. Fractures associated with neuropathic arthropathy in adults who have juvenile-onset neuropathic arthropathy in adults who have juve

3 Khan SA, Kurwa HA, Prentice MG. Atraumatic fractures in Type 1 diabetes. Diabet Med 1995; 12: $179-80$.

4 El-Khoury GY, Kathol MH. Neuropathic fractures in patients with diabetes mellitus. Radiology 1980; 134: $313-$ significant trauma. Before X-rays were performed, diagnoses such as cellulitis and gout were considered.

Various foot fractures have been described as complications of diabetic neuro-arthropathy, ${ }^{1-5}$ but fractures appear to be much less common in simple sensory neuropathy. Thus, El-Khoury and Kathol ${ }^{4}$ described six diabetic patients with neuropathic foot fractures, but four were associated with Charcot joints, and one with sepsis. Johnson, ${ }^{5}$ in a classic report from 1967, described fractures and joint injuries in 118 patients with neuropathic feet. Most, however, had tabes dorsalis, and only 10 of the series were diabetic. Details of all these cases were not included, but most appeared to be associated with neuro-arthropathy. More recently, Krentz and colleagues ${ }^{6}$ reported on four diabetic patients with neuropathic foot fractures, all of which were painful; one occurred with neuro-arthropathy. Cundy et $a l$ reported X-ray examination of 19 diabetic patients with severe neuropathy, compared with 22 diabetic control patients without neuropathy. Most patients had IDDM, and diabetes was of long duration (mean 21 years in the neuropathic group). Four neuropathic patients $(21 \%)$ had metatarsal fractures, and two other patients developed similar fractures in the 18 months following the study. There were no fractures in the control group. Though only two of the patients with fractures described related trauma, all fracture patients presented with an 'aching, hot, swollen foot'.

From the above review, it can be seen that in nearly all cases of diabetic neuropathic foot fractures, there is associated neuro-arthropathy, and also usually pain. Our patients are therefore unusual in that the fractures were entirely painless, occurred in the absence of trauma, and were not associated with neuroarthopathic joints. Fractures should therefore be considered in any patient with diabetic neuropathic feet who presents with foot swelling, regardless of the presence or absence of pain or a history of trauma. An X-ray is mandatory, and may prevent fruitless searches for alternative causes.

5 Johnson JTH. Neuropathic fractures and joint injuries. Pathogenesis and rationale of prevention and treatment. $\mathcal{F}$ Bone foint Surg 1967; $49 A$ of preven

6 Krentz AJ, Fitzgerald MG, Wright AD, Nattrass M Krentz AJ, Fitzgerald MG, Wright AD, Nattrass $M$.
Spontaneous fractures in patients with diabetic neuropathy Spontaneous fractures in patients with diabe
$\Im R$ Coll Physicians Lond $1989 ; 23: 111-3$.

7 Cundy TF, Edmonds ME, Watkins PJ. Osteopoenia and metatarsal fractures in diabetic neuropathy. Diabet Med 1985; 2: $461-4$. 